\title{
John Lewis Gaddis: On Grand Strategy
}

\author{
Leonardo Curzio*
}

No es frecuente encontrar libros que resuman, de manera brillante y redonda, una materia como la estrategia, ampliamente tratada en eruditos y descomunales manuales, como es el caso de autores tan reconocidos como Freedman, Luttwak o Paret. Gaddis ha conseguido la proeza de extraer, en un texto breve y asequible, la esencia de los grandes dilemas de la estrategia.

En efecto, el libro es ágil y disfrutable, incluso para lectores no especializados; refleja un conocimiento profundo de la temática abordada, cosa que se da por descontada en el gran historiador de la guerra fría y, además, condensa amplias horas de lectura, reflexión e interacción con académicos y tomadores de decisión. Es, por añadidura, un texto elegante con una singular sensibilidad literaria que aparece en múltiples y oportunas citas de Shakespeare, Scott Fitzgerald y otros gigantes de la literatura. Por supuesto, el libro sigue -con rigor pedagógico- una secuencia que conecta a Jerjes con Franklin D. Roosevelt y está articulado en torno a los grandes exponentes del pensamiento estratégico. Desde Heródoto hasta Tucídides, pasa revista a Maquiavelo y San Agustín, Tolstoi y Clausewitz y, presidiendo de toda la reflexión, el colosal y cada vez más valorado historiador del pensamiento político: Isaiah Berlin.

De Berlín, el autor retoma el muy conocido ensayo sobre la zorra y el erizo. El texto de Berlin, como es sabido, abre con una cita del poeta griego Arquíloco que dice: "La zorra sabe muchas cosas, pero el erizo sabe una importante". La diferencia esencial entre los dos animales refleja también la forma en que los humanos pueden razonar y comportarse ante un entorno agresivo e incierto. El zorro es sagaz y puede prever

\footnotetext{
* Investigador, Centro de Investigaciones sobre América del Norte (CISAN), Universidad Nacional Autónoma de México (unam), <leonardocurzio@gmail.com>.
} 
distintas reacciones, tiende a confiar en su habilidad y astucia para lidiar con un entorno amenazante. Por el contrario, el erizo sólo sabe replegarse sobre sí mismo ante cualquier circunstancia, pero lo hace muy bien, y tiene la certeza de que su reacción será eficaz. Los zorros son creativos y los erizos reactivos, igual que los líderes políticos o responsables de operar y tomar decisiones, que tienden a desplegarse audazmente o a encastillarse según sea su proclividad. De esta manera, la predictibilidad del comportamiento puede minar la creatividad (y la innovación) del tomador de decisiones en un entorno incierto y cambiante. El erizo tiende a ser más conservador porque ha aprendido lo básico; no requiere, por lo tanto, fomentar la colaboración o reforzar disciplinas creativas para alcanzar nuevas metas. Él sabe lo que tiene que hacer y lo hace de forma instintiva.

Los zorros, por el contrario, confían en sus predicciones. Son proclives incluso a sobrevalorar su intuición porque son capaces de procesar distintas fuentes de información y esbozar una composición del lugar con rapidez, cosa que les permite evaluar sus opciones en un entorno inestable y amenazante.

Los zorros son creativos y los erizos reactivos,

igual que los líderes políticos o responsables de operar y tomar decisiones.

Cada uno de los dos animales tiende a confiar en su habilidad innata, pues en el pasado han salido airosos de complicados lances. Sin embargo, también han encontrado escollos, los erizos buscan siempre actuar en función de sus prejuicios pensando en que todo evento será igual que el anterior y, en cualquier caso, la respuesta debe replegarse, como lo hizo Kutúzov frente al avance de la hasta entonces imbatible grande armée, pero hay otras circunstancias en las que el repliegue condena a la intrascendencia.

Por supuesto que hay variantes, matices y formas alternas de comportarse. Casi todos los líderes tienden a actuar de una manera u otra porque saben que lo único que no pueden hacer es paralizarse y, por consiguiente, pueden optar por un examen relativamente rápido del entorno y tratar de ofrecer nuevas soluciones al dilema que enfrentan o bien volver a los principios que dominan y reiterar la experiencia ancestral. En política exterior, el comportamiento del erizo es equivalente a atenerse a los principios constitucionales de forma mecánica y no arriesgar ni evaluar que cada caso requiere una nueva estimación de las aspiraciones y los recursos disponibles.

Un punto importante en la argumentación de Gaddis es el despliegue de la sencilla (pero deslumbrante) prueba de inteligencia propuesta 
por Scott Fitzgerald. Ésta permite calibrar a quienes tienen la habilidad de mantener dos ideas opuestas en su mente y conservar la capacidad de funcionar. Las mentes simples rechazan, de plano, las contradicciones, y a menudo se alteran con las disonancias que les resultan insoportables. Manejar los contrarios es una habilidad requerida para confeccionar y operar la estrategia, ya que facilita (al líder) extraer conclusiones cambiantes en el curso de la toma de decisión. No es sencillo comprender que la contradicción puede anidar en el pensamiento del estratega desde una concepción lineal y mecánica, pero lo cierto es que la mayor parte de los procesos de toma de decisión complejos no tienen, a diferencia de lo que ocurre con la lógica lineal, una solución fácil y evidente. Tampoco se tiene siempre toda la información -inteligencia- disponible en el momento oportuno. Esto debido a dos elementos primordiales. El primero porque la información no está disponible o porque los adversarios la esconden e incluso la alteran de manera deliberada (contrainteligencia). Si todos los líderes hubiesen dispuesto de una claridad meridiana -que es la que tenemos cuando leemos historia- sus decisiones hubiesen sido otras. Jerjes hubiese tomado otro curso de acción, Pericles lo hubiese hecho de otra manera, o cualquier otro líder que a lo largo de la historia ha tenido que enfrentar grandes decisiones en entornos nebulosos (o francamente contradictorios), sólo hubiese tenido que seguir una fórmula preestablecida y hubiese acertado.

Un aspecto crucial que Gaddis pone de relieve es el tema de la escala y lo que está en juego. Por eso se habla de la estrategia a secas y de la gran estrategia. Otra reflexión importante (que preside toda la obra) es aquella que tiene que ver con los recursos disponibles en cada país en un momento específico y la forma en que ese país se percibe a sí mismo, (la confianza o inseguridad) que varía en cada contexto diferente de la historia. Hay países o imperios que han decidido, a lo largo de la historia, edificar muros y, en cada caso, el debate es si esas murallas tienen un carácter ofensivo o defensivo, y eso, en última instancia, depende de la autopercepción que se tenga. Cuando flaquea la confianza en el propio poderío, incrementa la voluntad de amurallar el territorio. La tentación es milenaria, y el autor bucea en las profundidades de la historia para traer a colación paralelismos inquietantes. Los atenienses, por ejemplo, pretendían construir muros para salvar su territorio y conservar su poderío naval, mientras que los espartanos conseguían la seguridad con una ausencia completa de muros porque su ejército era el más poderoso de Grecia y,
Hay países o imperios que han decidido edificar muros, y el debate es si esas murallas tienen un carácter ofensivo o defensivo. 
Lo que la gran estrategia plantea es alinear las (potencialmente ilimitadas) capacidades de generar aspiraciones, con las (limitadas) capacidades que todo país tiene en un momento de su historia. en consecuencia, era capaz de disuadir a cualquier otro de atacar. Esparta confiaba en sus capacidades; Pericles envejecía y su inseguridad la transmitía a su pueblo. Estados Unidos, en su lento declinar, acaricia la idea de la muralla con un presidente de edad avanzada.

La estrategia, en definitiva, depende de un entorno cambiante que tome en cuenta el tiempo, el espacio y la escala, y obliga (al tomador de decisiones) a acompasar los objetivos con los medios disponibles. Un gran líder es capaz de cultivar grandes aspiraciones en el alma de su pueblo, pero si no desarrolla capacidades para conseguirlas, se convierte en un demagogo (o en un fracasado) en el mediano plazo. Mantener los pies en la tierra y evaluar en todo momento lo que se tiene es el ejercicio de pragmatismo básico que explica por qué una estrategia se impone sobre la otra. El estratega es, en esencia, un pragmático que juega con las opciones disponibles y las combina con sus aspiraciones.

Lo que la gran estrategia plantea es, en resumen, alinear las (potencialmente ilimitadas) capacidades de generar aspiraciones, con las (terrenalmente limitadas) capacidades que todo país tiene en un momento determinado de su historia. No hay posibilidad de tener una estrategia sostenible, duradera y eficaz, si no se conectan estos dos extremos.

Por otra parte, la revisión de la obra de Sun Tzu es una escala inevitable en un libro sobre estrategia. La célebre compilación de preceptos, recomendaciones y aforismos, le han dado al texto chino una notoriedad y ubicuidad totales. De las muchas recomendaciones que pueden espigarse de El arte de la guerra, figura aquella de que ésta última es un asunto vital y, por tanto, nunca debes ir a la misma sin reflexiones profundas. Sun Tzu puede ser trivial o profundo, según el plano de lectura que uno tenga. Por ejemplo, cuando dice que el ejército tiene la forma del agua y que en cuanto encuentra un punto débil puede avanzar sin resistencia, el razonamiento y la metáfora nos deslumbra, pero no nos dice cómo encontrar el punto débil. Sin embargo, lo que nos deja claro es que, cuando una idea simple se interconecta con otras igualmente simples, el entramado empieza a desarrollar una complejidad potencialmente infinita. Como miles de hilos entrelazados se convierten en una alfombra.

El libro tiene un muy jugoso capítulo de historia romana en el que dos asuntos fundamentales son revisados minuciosamente. El primero, es el arte de maniobrar para conseguir un objetivo. La política tiene sus tiempos y habilidades. Gaddis estudia las virtudes del navegante, quien sabe usar los vientos a su favor y puede recorrer grandes distancias; en 
contraste, el horticultor, más cercano al político (como oficio), no se mueve con celeridad, pero sabe usar el tiempo para que las plantas crezcan y den fruto. En la descripción de la vida de Augusto recuerda que un príncipe puede heredar, en un día, un reino o un imperio, pero le llevará toda su vida dominar el arte del mando y la paciencia necesaria para hacerlo perdurar. La longevidad de los imperios nunca es un asunto automático, sino, por el contrario, un arte que se debe cultivar, a veces con contradicciones aparentes y en otras combinando opuestos o mezclando culturas para obtener frutos más jugosos y resilientes. La grandeza también hay que cultivarla para conseguir proyectar así el mando en una trayectoria ascendente, y así coronar la trayectoria como Augusto, quien recibió una Roma hecha en barro y heredó a sus sucesores una Roma marmórea.

Otros dos capítulos del libro se centran en dos mancuernas muy relevantes que merecen una revisión puntual. Una es San Agustín, el prototipo del erizo, que nunca estuvo a gusto con las contradicciones, y la otra es Maquiavelo, el zorro, quien entendía que la rigidez moral impedía, a quien ostenta el mando, ejercerlo con naturalidad y ligereza. A partir de estas dos figuras intelectuales o pivotes -como él los llama, es decir, puntos de inflexión- de la historia del pensamiento político, el autor desarrolla una lectura cuidadosa de la reina Isabel y de Felipe II.

Un príncipe debe gobernar con flexibilidad y balancear opiniones y contradicciones, además, debe optar por una amplia paleta de opciones que van desde eliminar a un adversario, hasta mezclarse con él. Todo estratega debe recordar que en una guerra siempre hay un costo (casi nunca insignificante) para las partes en conflicto, por eso debe sopesar con enorme cuidado que el objetivo a perseguir no supere el costo en el que incurre aquel que organiza la guerra. El estadista (o el príncipe) enfrenta siempre los dilemas de los intereses superiores y los males menores. Hay ocasiones en las que convivir con el mal menor es mejor que ir a una guerra destructiva, o bien entender que, en muchas ocasiones, las fuerzas de la historia son infinitamente más potentes que las decisiones de un líder catapultado por la voluntad de un pueblo enardecido que clama venganza. El buen estratega sabe que las batallas debilitan a las dos partes en litigio y los príncipes deben valorar si pueden tener "puntos culminantes" que cambien la correlación de fuerzas o bien, en el mismo esfuerzo, el atacante puede perder su propia fuerza, como paradójicamente sucedió con la campaña napoleónica en Rusia, donde los franceses se derrotaron por extenuarse a ellos mismos. Llevar a la guerra a un pueblo supone
La longevidad de los imperios nunca es un asunto automático, sino un arte que se debe cultivar combinando opuestos o mezclando culturas para obtener frutos más jugosos y resilientes. 
La estrategia nunca se aplica en terreno plano

y estable, la

situación es permanentemente cambiante, y se precisa una interacción fluida entre teoría y práctica. superar el instinto natural de homo sapiens de resistirse a morir, y persuadirlo de que morir por la patria (o por el rey) vale la pena; por eso el rey debe pensar muy bien sus opciones cuando confronta los dilemas de la planeación y la fricción, la fuerza y la política, el amor y el odio. Esos son los grandes dilemas de la estrategia que retoma en capítulos posteriores comentando magistralmente a Tolstoi y Clausewitz.

En diferentes momentos de la historia, Gaddis ejemplifica que un príncipe debe, de la misma manera que lo hicieron grandes presidentes de Estados Unidos, balancear opiniones e incluso manejar durante algún tiempo una duplicidad que puede ser muy eficaz para cambiar equilibrios y correlaciones de fuerza en coyunturas cambiantes. La estrategia se mueve conforme se mueve el entorno variable y fluye información que valida, contextualiza, refuta o profundiza una línea de acción previamente adoptada. El peor error de un estratega es creer que todo se va a mantener estable. La variación es la norma. Una decisión cambia el propio comportamiento y el del oponente.

No siempre es fácil, para un tomador de decisión, optar por observar lo que ocurre en la realidad, abstraerse y apoyarse en teorías o capítulos previos de la historia para desplegar su estrategia. Las batallas tienen distintos momentos que debilitan física y moralmente a una de las partes. Nunca poder alguno ha tenido una línea ascendente sin interrupción. Todas las batallas (y particularmente en una democracia) suscitan valoraciones diversas, juicios encontrados y opiniones francamente discordantes que obligan a presidentes como Lincoln a tomar decisiones en contextos sumamente adversos, porque la combinación de elementos nunca es totalmente diáfana. El líder debe tener una sensibilidad ecológica y vincular la estrategia con la imaginación, a través de rápidos esbozos o croquis que permitan contemplar opciones de colaboración y conexión con otros factores que reduzcan la fricción. Otra particularidad de la estrategia es que nunca se aplica en terreno plano y estable, la situación es permanentemente cambiante y, por tanto, se precisa una interacción fluida entre teoría y práctica, entre entrenamiento e improvisación y entre el pensamiento especulativo y práctico. El estratega vive, en suma, en medio de breves momentos de calma y en la tempestad, en la que se juega su baraja completa.

Y, como toda baraja, la lista incluye cartas buenas y malas, según las circunstancias. A veces la fuerza permite conseguir más rápido un objetivo que la política, pero la política puede permitir conseguir objetivos 
con menor costo humano y más duraderos; por eso la victoria no siempre es algo que pueda obtenerse en todos los frentes. Hay guerras que se ganan con un enorme costo, como la que Gran Bretaña ganó a Francia por la disputa de las Américas (la del azúcar y la nieve), la cual terminó desgajando el imperio británico y concluyó con la independencia de Estados Unidos.

Es interesante, igualmente, el tratamiento de los dilemas más clásicos de la estrategia moderna que fueron delineados por el famoso "Hinterland", el control del pivote geográfico (Mackinder) o el poderío naval (Mahan), que ha asegurado a las dos últimas potencias, es decir, Estados Unidos y Gran Bretaña, la preservación de su hegemonía.

El texto repara nuevamente en el multicitado memorándum Crowe que, como es sabido, anticipa que el ascenso prusiano en términos de poder naval y desarrollo industrial llevaría a una inevitable confrontación con la Gran Bretaña por el choque de intereses. Es apasionante releer la historia del pensamiento estratégico sabiendo lo que ocurrió no sólo por un divertimento intelectual, sino porque esa reflexión resulta absolutamente reveladora al releer los textos que recientemente han examinado el ascenso chino a la luz del eventual choque de intereses entre Estados Unidos y China. El primero es el muy comentado libro de Kissinger y el segundo, La trampa de Tucídides de Graham Allison.

El estudio de los grandes presidentes de Estados Unidos contempla un dilatado periodo que va desde el revalorado Quincy Jones (por cierto, Gaddis parece reprochar a Tolstoi no haberlo incluido en sus descripciones de La guerra y la paz) y termina con Franklin Delano Roosevelt, pasando naturalmente por Abraham Lincoln y Woodrow Wilson. No me detengo en cada uno de ellos porque finalmente el libro concluye con una amplia reflexión sobre la dirección de la historia y los eventos que controlan el curso de los acontecimientos en los que Tolstoi adquiere proporciones colosales como pensador, no sólo como literato.

El libro es, en definitiva, una referencia en la materia que será de gran utilidad para docentes e investigadores que podrán reorientar y recalibrar sus prioridades y dilemas con esta obra, breve y potente de un Gaddis que está en plena madurez intelectual.
Es apasionante releer la historia del pensamiento estratégico sabiendo lo que ocurrió no sólo por un divertimento intelectual, sino porque esa reflexión resulta absolutamente reveladora. 


\section{FUENTES}

\section{Allison, Graham}

2017 Destined for War: Can America and China Escape Thucydides's Trap?, Boston, Houghton Mifflin Harcourt.

BERLIN, ISAIAH

2012 El erizo y la zorra. Tolstoi y su visión de la historia, Barcelona, Ediciones Península.

FREEDMAN, LAWRENCE

2013 Strategy. A History, Nueva York, Oxford University Press.

GADDIS, JOHN LEWIS

2018 On Grand Strategy, Nueva York, Penguin.

KISSINGER, Henry

2011 On China, Nueva York, Penguin.

LUTTWAK, EDWARD

1987 Strategy: The Logic of War and Peace, Cambridge, Belknap Press / Harvard University Press.

Paret, Peter et al., eds.

1986 Makers of Modern Strategy from Machiavelli to the Nuclear Age, Nueva Jersey, Princeton University Press. 